\title{
In Silico Study of Human Gap Junction Beta-2 Protein by Homology Modeling
}

\author{
Abida Shehzadi ${ }^{1}$ and Khalid Masood ${ }^{1,2 *}$ \\ ${ }^{1}$ Bioinformatics Wing, Center of Excellence in Molecular \\ Biology, University of the Punjab, Lahore, ${ }^{2}$ Medical \\ Research and Development Division, Informatics Com- \\ puter and Control Centre, Lahore, India
}

\begin{abstract}
Asp66his, Asp54Lys, and Asp50Asn are mutations in connexin 26 that are observed in the clinic and give rise to autosomal dominant syndromes. They are the result of point mutations in the human gap junction $\beta-2$ gene. In order to investigate the structural mechanism of Bart-Pumphrey Syndrome, Keratitis-Ichthyosis-Deafness Syndrome, and Vohwinkel Syndrome, homology modeling was carried out. Asp66 has direct contact with Asn62 by two hydrogen bonds in the wild-type protein, and in Asp66His, the biggest change observed is a tremendous energy increase caused by hydrogen bond breakage to Asn62. Shifts in the side chain and new hydrogen bond formation are observed for Lys54 compared to the wild-type protein (Asn54) and result in closer contact to Val84. Asp50Asn causes a significant decrease in bond energy, and residual charge reversal repels the ion and metabolites and, hence, inhibits their transportation. Such perturbations are likely to be a factor contributing to abnormal functioning of ion channels, resulting cell death and disease.
\end{abstract}

Keywords: Bart-Pumphrey syndrome, connexin 26, gap junction, $\beta-2$ protein, hearing impairment, Keratitis-Ichthyosis-Deafness syndrome, knuckle pads, leukonychia, vohwinkel syndrome

\section{Introduction}

Hearing impairment or hearing loss is a full or partial decrease in the ability to perceive sounds, induced by various biological (Tremblay and Ross, 2007), environmental (Eyken et al., 2007), and genetic factors. Various dominant and recessive genes subsist that induce inherited hearing impairments (Laer et al., 2001). Kelsell et al. 1997 reported a GJB2 mutation, leading to hearing

*Corresponding author: E-mail khalid@cemb.edu.pk Tel +92-42-35293141, Fax +92-42-35293149 Accepted 13 June 2010 deterioration.

The gap junction $\beta-2$ gene (GJB2) is situated on the long arm ( $q$ arm) of human chromosome 13 at a position between 11 and 12 (Castillo et al., 2005). The GJB2 gene encodes for the connexin protein (GJB2 protein) (Cx26) (Latting et al., 2008). Gap junction $\beta-2$ protein, commonly known as connexin 26 (Cx26), belongs to a family of structurally related transmembrane proteins that mediate intracellular transport of various ions and molecules (Sosinsky, 1995). Various connexin proteins assemble with each other and form gap junctions. Gap junctions are the clusters of intercellular channels involved in direct communication between cells. GJB2 mutations result in altered protein sequences. Alterations in the protein sequence are the predominant cause of inherited, sensorineural deafness (Zelante et al., 1997).

Immunohistochemistry of inner ear tissues has shown that connexin 26 and connexin 30 colocalize (Forge et al., 2002; Lautermann et al., 1998). Connexin 26 has a structural resemblance to innexins that form gap junctions in invertebrates but has quite a different protein sequence. The molecular weight of connexin is about 26 $\mathrm{KDa}$, a product of the GJB2 gene. Connexin exists in a dynamic cycle of synthesis and replacement because of a short life span of a few hours (Musil, et al., 1993). Connexin 26 is found in cells throughout the body, particularly in the inner ear and the skin, and permits the transport of potassium ions and small molecules in neighboring cells (Castillo et al., 2005). Its presence in the cochlea is associated with hearing.

GJB2 mutations are the cause of recessive and dominant forms of deafness (Laer et al., 2001), affecting 1 in 1000 children (Bitner-Glindzicz, 2002). About 20 mutations of gap junction $\beta-2$ have been described as being related to diseases (Abe et al., 2000) and various syndromes, such as Bart-Pumphrey Syndrome, KeratitisIchthyosis-Deafness Syndrome, and Vohwinkel Syndrome. (Richard et al., 2004; Snoeckx et al., 2005; Yotsumoto et al., 2003). The mutations alter the amino acid sequence of connexin 26 and result in impaired functioning of the protein associated with ion channels, especially. In fact, a range of phenotypic presentations of autosomal dominant and recessive gap junction $\beta-2$ gene mutations are intriguing. Such mutations result in an unstable or malformed protein, unable to form gap junctions, or they result in a modified protein that builds dysfunctional gap junctions. So, the falsified or modified connexin 26 curbs the normal arrangement of gap junc- 
tions and, hence, their proper functioning, affecting the transition of sound waves to neural impulses.

So, the present study was carried out to highlight the structural changes, especially the hydrogen bonding, bond angles, bond length, force field energies, and PI values, because such forces and factors are considered to be contributing to the effect on amino acid residues, their stability, and normal functioning (Karaguller et al., 2004; Talley et al., 2008).

\section{Structure of human gap junction $\beta-2$ protein}

The X-ray crystallographic structure of connexin 26 is not known. But, the protein sequence and basic protein structure are known and well characterized (Fig. 1).

\section{Methods}

\section{Homology modeling}

Sequence Analysis: The primary sequence of human connexin 26 (primary accession no. P29033) was retrieved from SWISS-Prot (Bairoch and Apweiler, 1997). Using in silico tools, a theoretically designed homology model (1xir) was obtained from Protein Data Bank (PDB). Homology modeling can be described in four steps: (A) identification of a homolog from PDB whose structure is known; (B) alignment/positioning of our query sequence to the template or model sequence; $(C)$ construction of the replica/model based on the alignment; and (D) entrance and refinement of the model. A

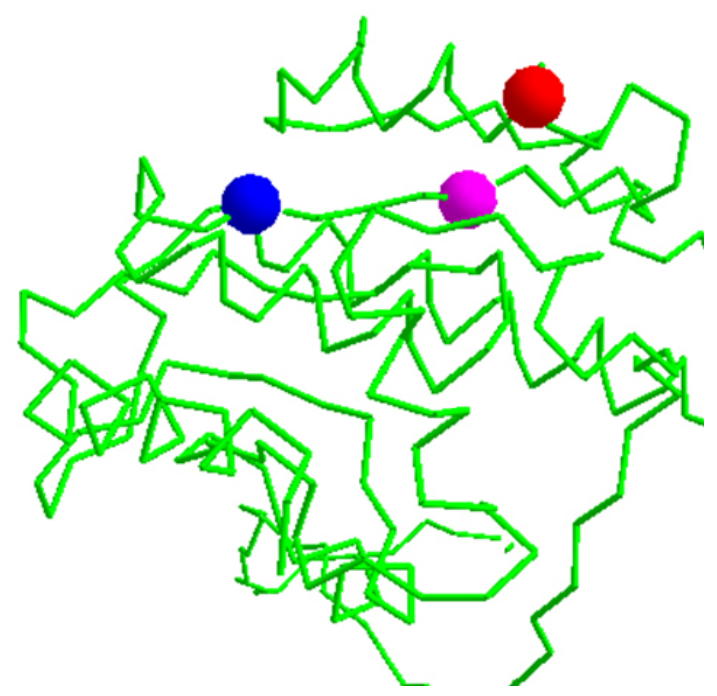

Fig. 1. Gap Junction $\beta-2$ Protein (Connexin 26) (mutation sites are highlighted: Asp66 in red, Lys54 in pink, and Asp 50 in blue). sequence similarity of $30 \%$ to a known protein structure being often predicted and is equivalent to a low-resolution X-ray structure (Xiang, 2006). The 3D coordinates of the template used were available.

\section{Mutational studies}

By using Swiss Protein Deep Viewer, various structural implementations were carried out from the coordinate file for the selected amino acids-Asp66His, Asn54Lys, and Asp50Asn-involved in obvious clinical syndromes (Fig. 1). Asp66, Asn54, and Asp50 were mutated to His66, Asn54, and Asp50, respectively, and a study was carried out to observe changes in hydrogen bonds, bond lengths, angles, and rotations. Energy calculations for wild-type and mutated amino acids were made by using the GROMOSS96 implementation of the Swiss Protein Deep Viewer. The PI values of the individual amino acid residues, wild-type and mutant, were compared on the basis of an available table (Williams et al., 1987).

\section{Results}

In nature, a protein is stabilized by protein folds into one or more specific conformations to perform biological functions. The specific conformations are driven by various interactions, such as hydrogen bonding, bond angles, and various forces. The 226 amino acids of connexin 26 are known. The 3D structure of connexin 26 is well known and was obtained from Protein Data Bank. Mutations in the gap junction $\beta-2$ gene cause a substitution of different amino acids of connexin 26 and result in various syndromes. In the present work, 3 amino acids of the E1 domain of the protein were selected to determine the characteristic changes affecting the physiology of connexin 26 (Fig. 2).

\section{Asp66His}

Asp66His causes a hydrogen bond breakage to Asn62 (Table 1), resulting in a significant increase in energy for bonds $(18.494 \mathrm{KJ} / \mathrm{mol}$ for mutant compared to 5.516 $\mathrm{KJ} / \mathrm{mol}$ for wild-type). The angular energy increased by $2.457 \mathrm{KJ} / \mathrm{mol}$ for His66. The CG1-CB1 rotation for His66 changed the CA1-CB1-CG1 angle from $108.76^{\circ}$ for the wild-type to $115.05^{\circ}$ for the mutated amino acid (Table 2). The CG1-CB1 bond rotation disturbs the existing hydrogen bond (2.67 $\AA$ ) to Asn62 (Fig. 2A, 2B). The aromatic ring of His66 reduces the distance to Pro70 (CD1-CB1 distance, $4.98 \AA$ for wild-type to CE11-CG1 $4.06 \AA$ bond length for the mutation). Another important change observed is the shift in normal charges of the residue from negative to positive, with the increase in PI 


\section{(2A)}
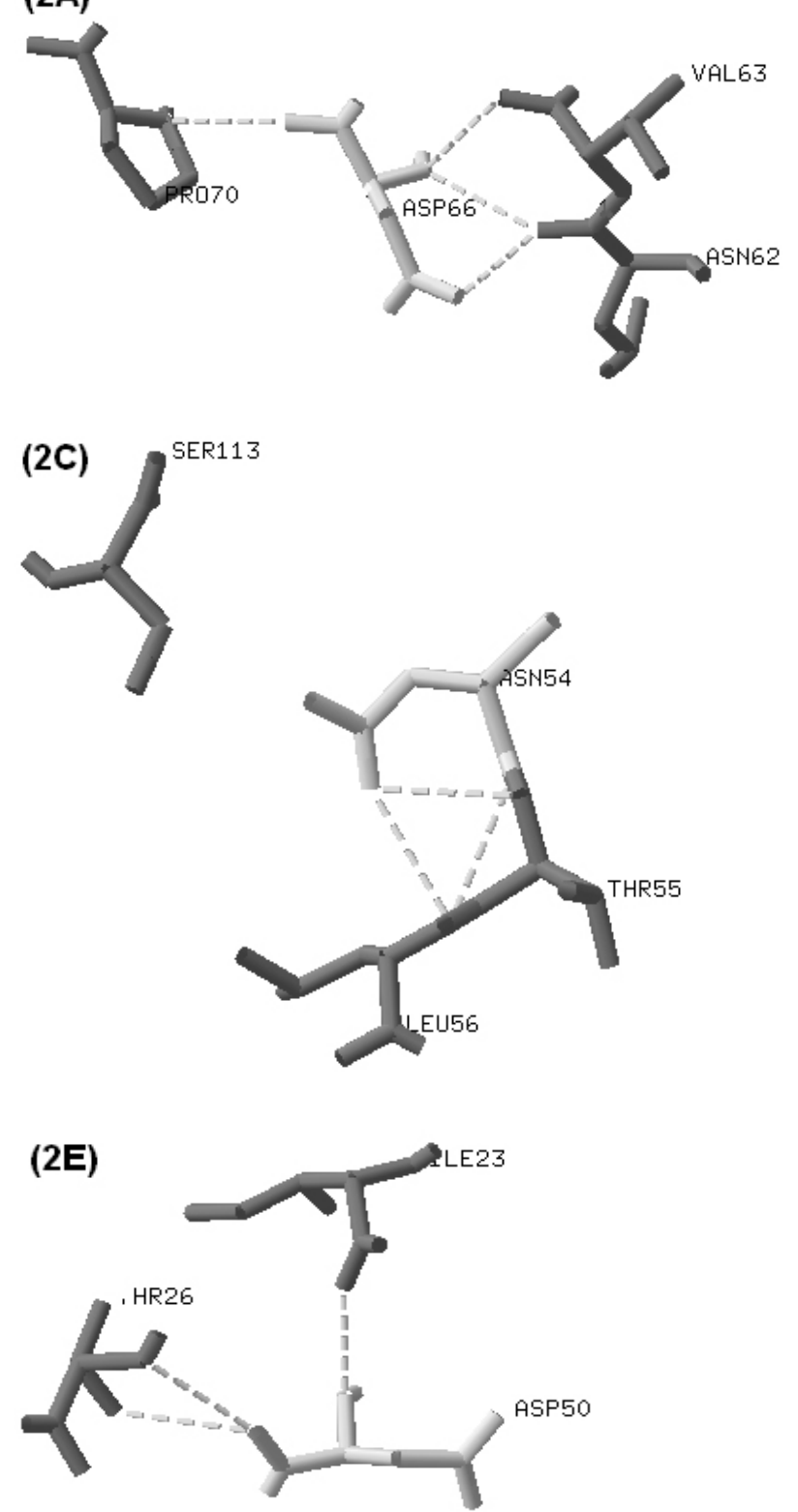

(2B)

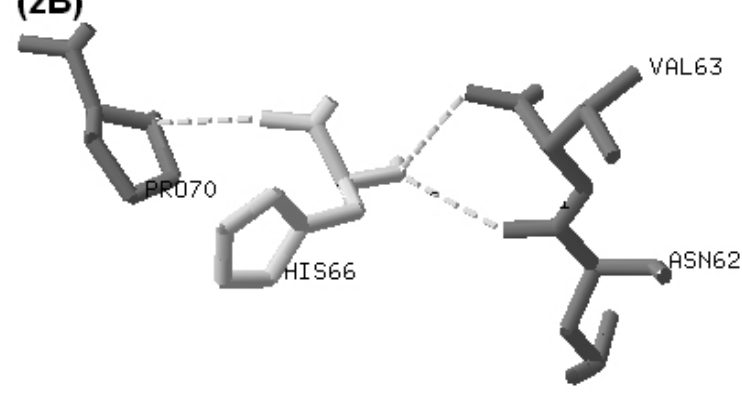

(2D)

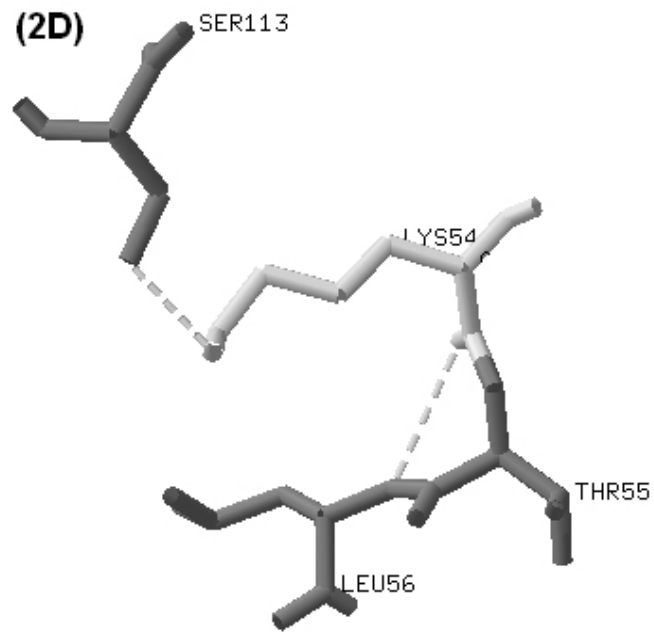

(2F)

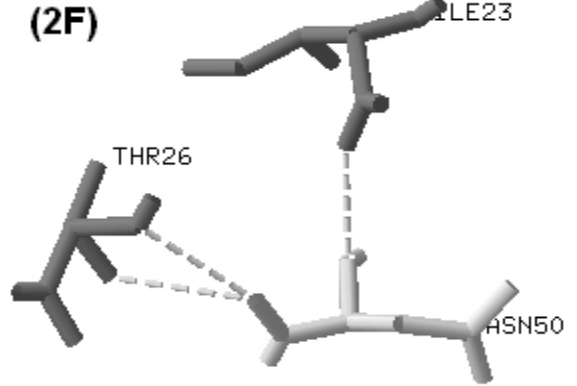

Fig. 2. (A, B) Comparative models of Asp66His (A-Wild-type, B-Mutated). (C, D) Comparative models of Asp50Asn (CWild-type, D Mutated). (E, F) Comparative models of Asp50Asn (E-Wild-type, F-Mutated).

value from 2.77 to 7.59 . But, the shift in hydrogen bonding is enough to play a considerable role in affecting the normal interaction of protein residues and, ultimately, the overall charge of ion channels and their interactions with ions and metabolites associated with transportation functioning.

\section{Asn54Lys}

The high-molecular-weight (114) polar amino acid aspar- agine affects the structure of proteins in a highly specific manner by providing a strong driving force for folding. Moreover, it possesses interesting hydrogen bond properties that resemble the backbone peptides. A missense mutation, Asn54Lys, causes hydrogen bond breakage to Leu56 (3.12 $\AA$ ) and Thr55 (3.05 $\AA$ ) (Fig. 2C, 2D). The hydrogen bond breakage results in a shift in tortional energy $(4.702 \mathrm{~kJ} / \mathrm{mol}$ for wild-type to $7.002 \mathrm{~kJ} / \mathrm{mol}$ for mutant) and a tremendous decrease in electrostatic potential energy by $37.5 \mathrm{~kJ} / \mathrm{mol}(52.92 \mathrm{~kJ} / \mathrm{mol}$ for wild-type 
Table 1. Measurement of hydrogen bonds $(\AA)$ of target amino acids

\begin{tabular}{|c|c|c|c|c|c|c|c|c|c|}
\hline \multirow{2}{*}{\multicolumn{2}{|c|}{ Target amino acid }} & \multicolumn{8}{|c|}{ Amino acids involved in Hydrogen bonding and bond length $(\AA)$} \\
\hline & & \multirow{2}{*}{$\frac{\text { Leu23 }}{-}$} & \multirow{2}{*}{$\begin{array}{c}\text { Thr26 } \\
--\end{array}$} & \multirow{2}{*}{$\begin{array}{c}\text { Thr55 } \\
-\end{array}$} & \multirow{2}{*}{$\frac{\text { Leu56 }}{-}$} & \multirow{3}{*}{$\begin{array}{c}\text { Asn62 } \\
2.67\end{array}$} & \multirow{2}{*}{$\begin{array}{c}\text { Val63 } \\
3.21\end{array}$} & \multirow{2}{*}{$\begin{array}{c}\text { Pro70 } \\
3.18\end{array}$} & \multirow{2}{*}{$\frac{\text { Ser113 }}{-}$} \\
\hline Wild type & Asp66 & & & & & & & & \\
\hline & & & & & & & & & \\
\hline & Asn54 & - & - & 3.05 & 3.26 & - & - & - & - \\
\hline & & & & & 3.12 & & & & \\
\hline & Asp50 & 2.73 & 3.22 & - & - & - & - & - & - \\
\hline & & & 3.12 & & & & & & \\
\hline \multirow[t]{4}{*}{ Mutated type } & His66 & - & - & - & - & 3.04 & 3.21 & 3.18 & - \\
\hline & Lys54 & - & - & - & 3.26 & - & - & - & 2.39 \\
\hline & Asn50 & 2.73 & 3.22 & - & - & - & - & - & - \\
\hline & & & 3.12 & & & & & & \\
\hline
\end{tabular}

Table 2. Energy calculation $(\mathrm{KJ} / \mathrm{mol})$ for various parameters of wild-type \& mutant amino acids using the GROMOS96 implementation of Swiss-PDB Viewer

\begin{tabular}{llllllrrr}
\hline \multicolumn{2}{c}{ Targeted amino acids } & Bonds & Angles & Tortion & Improper & Non bonded & Electrostatic & Total energy \\
\hline \multirow{2}{*}{ Wild type } & Asp66 & 5.516 & 3.583 & 1.227 & 0.219 & -14.80 & -11.09 & 6946.490 \\
& Asn54 & 7.729 & 1.841 & 4.702 & 1.838 & -20.16 & 52.92 & 6946.490 \\
\multirow{6}{*}{ Mutated type } & Asp50 & 63.585 & 6.062 & 5.511 & 0.133 & -5.58 & 11.46 & 6946.490 \\
& His66 & 18.494 & 6.04 & 0.763 & 0.270 & -23.43 & -10.04 & 6946.775 \\
& Lys54 & 5.777 & 1.421 & 7.002 & 1.842 & 93.29 & 15.42 & 7316.498 \\
& Asn50 & 6.228 & 3.332 & 6.171 & 0.031 & 1.92 & 8.16 & 6811.053 \\
\hline
\end{tabular}

to $15.42 \mathrm{~kJ} / \mathrm{mol}$ for the mutation), along with a decrease in energy for bonds $(7.729 \mathrm{~kJ} / \mathrm{mol}$ for wild-type to 5.777 for mutant) and angles $(1.841 \mathrm{~kJ} / \mathrm{mol}$ for wild-type and $1.421 \mathrm{~kJ} / \mathrm{mol}$ for mutant) (Table 1 \& 2). The additional methyl groups (CD1 and CE1) of the mutant Lys54 side chain, compared to the wild-type Asn54 residue, results in much closer contact with the adjacent Val84 side chain $(2.98 \AA$ for mutant compared to $4.21 \AA$ for wild-type) and forms a new hydrogen bond (2.39 $\AA$ ) to the carbonyl group of Ser113 (Fig. 2C, 2D). The changes significantly decrease the electrostatic energy with a minimal change in CA1-CB1-CG1 bond angle $\left(109.53^{\circ}\right.$ to $\left.109.54^{\circ}\right)$ but increase the energy of the whole protein considerably from $6,946.490 \mathrm{~kJ} / \mathrm{mol}$ for wild-type to $7,316.498 \mathrm{~kJ} / \mathrm{mol}$ for the mutated protein (Table 2). In addition, a connexin 26 mutation, Asn54 to Lys, shifts the interaction from 114 Glu to the CA and CG atoms of the protein's polar amino acid residue 110 Glu at a cutoff score of 2 with an additional increase in PI value from 5.41 for wild-type to 9.47 for the mutated residue and a charge reversal from a neutral to basic residue with a strong positive charge. The positively charged residue repels the positive ions and metabolites and thus impairs trafficking through ion channels of connexin proteins. A decrease in signal for the next pathway causes syndromes and hearing impairment.

\section{Asp50Asn}

Mutations leading to Asp50Asn apparently do not affect peptide bonds or hydrogen bonding (Fig. 2E, 2F) but significantly rotate the CA1-CB1-CG1 bond angle from $105.45^{\circ}$ for wild-type to $111.17^{\circ}$ for the mutated protein. The CG1-CB1 rotation cause a tremendous decrease in energy for bonds $(63.585 \mathrm{~kJ} / \mathrm{mol}$ for wild-type to 6.228 $\mathrm{kJ} / \mathrm{mol}$ for mutant), and electrostatic energy decreases by $3.3 \mathrm{~kJ} / \mathrm{mol}(11.46 \mathrm{~kJ} / \mathrm{mol}$ for wild-type to $8.16 \mathrm{k} / \mathrm{mol}$ for the mutant) with an overall decrease in the energy of the protein from $6946.490 \mathrm{~kJ} / \mathrm{mol}$ to $6811.053 \mathrm{~kJ} / \mathrm{mol}$ (Table 2). In addition, the connexin 26 mutation Asp50Asn results in a considerable increase in $\mathrm{PI}$ value from 2.77 in the wild-type to 5.41 for the mutated residue. This inhibits the Van der Waals interaction of the OD1 and OD2 atoms of the Asp50 side chains to the backbone oxygen atom of Glu47 at a cutoff score of 2. Alterations in atomic interaction and a charge reversal from negative to neutral result in impaired trafficking of positive ions and metabolites, such as calcium and potassium ions, with reduced transportation and signaling to the next pathways and, ultimately, cell death. 


\section{Discussion}

The long arm of human chromosome 13 holds a very important gene, GJB2, related to proper hearing (Castillo et al., 2005). The gene GJB2 translates into the connexin protein, which belongs to the connexin family in vertebrates. One of the proteins, connexin 26, transcribed by the gap junction $\beta-2$ gene, belongs to a group of structurally similar trans-proteins that assemble each other and form gap junctions (Soninsky, 1995). This protein is colocalized to connexin 30 and permits the transfer of ions and small molecules in their adjacent cells. In such a way, the protein couples the various cells both metabolically and electrically and maintains the cellular homeostasis (Mahasneh and Battah, 2006). Connexin 26 mutations are the cause of nonsyndromic recessive and dominant forms of hearing impairment (Kelsell et al., 1997). A point mutation at nucleotide 162 in codon 54 changes $C$ to $A$. This substitution leads to the replacement of the evolutionarily conserved asparagine 54 to an electronegatively charged lysine in the first expended loop of connexin 26 (Richard et al., 2004). The resultant mutation destroys the hydrogen bond from the amide group of Leu56 (Fig. 2D). Additional methyl groups of Leu54 extend to Ser113, and the carbonyl group of Ser113 shares a hydrogen bond with the Lys54 amide group (Fig. 2D). Such subtle changes alter the energy of the whole protein from $6946.490 \mathrm{~kJ} / \mathrm{mol}$ to $7316.498 \mathrm{~kJ} / \mathrm{mol}$ (Table 2). These changes might be involved in reducing the expression of connexin 26, causing Kunckle pads and leukonychia (Bart et al., 1967). Affected family members suffer from thickened skin of the palms and soles in early childhood (Richard et al., 2004). The mutation Asn54Lys disturbs the hydrogen bonds and seems to be a contributing factor toward reduced epidermal expression of connexin 26, also involved in Bart-Pumphrey Syndrome (Richard et al., 2004),

The dominant point mutation of gap junction $\beta-2$, causing Asp50Asn, significantly reduces the energy for bonds $(63.585 \mathrm{~kJ} / \mathrm{mol}$ for wild-type to $6.228 \mathrm{~kJ} / \mathrm{mol}$ for mutant). The CB1-CG1 bond rotation affects the angle ( $105.45^{\circ}$ for wild-type to $111.17^{\circ}$ for mutant) and the decrease in the force field energy of the protein from $6946.490 \mathrm{~kJ} / \mathrm{mol}$ to $6811.053 \mathrm{~kJ} / \mathrm{mol}$ (Table 2). The substitution of the conserved residue aspartic acid 50 by asparagine (Asp50Asn) in the first extracellular domain of connexin 26 causes Keratitis-Ichthyosis-Deafness Syndrome (Yotsumoto et al., 2003). This mutation is likely to be the factor that disturbs the communication of ions, metabolites, and signaling molecules in neighboring cells and affects homeostasis by disturbing the bonding and energies (Saez et al., 2000). Charge reversal and the reduced distance of His66 to Pro70 due to Asp66His alter the normal protein bonding (Fig. 2B), causing Vohwinkel syndrome (Snoeckx et al., 2005). This might result in impaired trafficking of connexin 26, its assembly with other proteins, and docking with adjacent cells (Maestrini, et al., 1999; Marziano, et al., 2003). Normally, connexin assembles at the planer of the plasma membrane involved in the formation of the gap junction plaque. Asp66His enlarges the CA1-CB1CG1 angle from $108.76^{\circ}$ to $115.05^{\circ}$. Such factors might be involved in contributing to the plane of connexin 26 , disturbing the members of the whole connexin unit, which ultimately affects membranous communication and results in hearing loss and skin diseases.

\section{Conclusion}

Connexin 26 is an important protein involved in normal hearing. Mutations affect the protein's function by disturbing the associated factors. However, similar to various other proteins, normal functioning of connexin 26 is associated with a range of factors. Hydrogen bonding, residual energies, atomic angles, and residual charges are the main contributing factors that affect ion channels and their transportation. This significant increase in $\mathrm{PI}$ value is an additional cause of charge reversal of amino acid residues, which repels ions and metabolites and their passage through ion channels, inhibiting the next signaling pathway and causing syndromes. So, this study could be used as a reference for establishing a mechanism that could inhibit the repletion of ions and metabolites but push them back on their normal track.

\section{References}

Abe, S., Usami, S., Shinkawa, H., Kelley, M.P., and Kimberling, J.W. (2000). Prevalent connexin 26 gene (GJB2) mutations in Japanese. J. Med. Genet. 37, 41-43.

Bairoch, A., and Apweiler, R. (1997). The SWISS-PROT protein sequence data bank and its supplement TrEMBL. Nucl. Acids Res. 25, 31-36.

Bart, R.S., and Pumphrey, R.E. (1967). Knuckle pads, Leukonychia \& Deafness. A Dominantly Inherited Syndrome. N. Engl. J. Med. 276, 202-207.

Bitner-Glindzicz, M. (2002). Hereditary deafness and phenotyping in humans. Br. Med. Bull. 63, 73-94.

Castillo, J.F., Rodríguez-Ballesteros, M., A'Ivarez, A., Hutchin, T., Leonardi, E., Oliveira, A.C., Azaiez, H., Brownstein, Z., Avenarius, R.M., Marlin, S., Pandya, A., Shahin, H., Siemering, R.K., Weil, D., Wuyts, W., Aguirre, A.L., Martín,Y., Moreno-Pelayo, A.M., Villamar, M., Avraham, B.K., Dahl, M.H., Kanaan, M., Nance, E.W., Petit, C., Smith, H.J.R., Camp, V.G., Sartorato, L.E., Murgia, A., Moreno, F., and Castillo, I. (2005). A novel deletion involving the connexin-30 gene, del (GJB6-d13s1854), found in trans with mutations in the GJB2 gene (connexin-26) in subjects with DFNB1 non-syndromic hearing impair- 
ment. J. Med. Genet. 42, 588-594.

Denoyelle, F., Lina-Granade, G., Plauchu, H., Bruzzone, R., Chaib, H., Levi-Acobas, F., Weil, D., and Petit, C. (1998). Connexin 26 gene linked to a dominant deafness. Nature 393, 319-320.

Eyken, V.E., Camp, V.G., and Laer, V.L. (2007). The Complexity of age-related hearing impairment: contributing environmental and genetic factors. Audiol. Neurotol. 12, 345-358.

Forge, A., Becker, D., Casalotti, S., Edwards, J., Marziano, N., and Nickel, R. (2002). Connexins and gap junctions in the inner ear. Audiol. Neurootol. 7, 141-145.

Karagüler, G.N., Sessions, B.R., Moreton, M. K., Clarke, R. A., and Holbrook, J.J. (2004). Estimating the energetic contribution of hydrogen bonding to the stability of Candida methylica formate dehydrogenase by using double mutant cycle. Biotechnol. Lett. 26, 1137-1140.

Kelsell, D.P., Dunlop, J., Stevens, H.P., Lench, N., Liang, J.N., Parry, G., Mueller, R.F., and Leigh, I.M. (1997). Connexin 26 mutations in hereditary non-syndromic sensorineural deafness. Nature 387, 80-83.

Laer, V.L., Coucke, P., Mueller, F.R., Caethoven, G., Flothmann, K., Prasad, D.S., Chamberlin, P.G., Houseman, M., Taylor, R.G., Heyning, V.M.C., Fransen, E., Rowland, J., Cucci, A.R., Smith, H.J.R., and Camp, V.G. (2001). A common founder for the 35delG GJB2 gene mutation in connexin 26 hearing impairment. J. Med. Genet. 38, 515-518.

Lattig, M.C., Gelvez, N., Plaza, S.L., Tamayo, G., Uribe, J.I., Salvatierra, I., Bernal, J.E., and Tamayo, M.L. (2008). Deafness on the island of Providencia - Colombia: different etiology, different genetic counseling. Genet. Couns. 19, 403-412.

Lautermann, J., ten Cate, W.J., Altenhoff, P., Grummer, R., Traub, O., Frank, H., Jahnke, K., and Winterhager, E. (1998). Expression of the gap-junction connexins 26 and 30 in the rat cochlea. Cell Tissue Res. 294, 415-420.

Mahasneh, A.A., and Battah, R.M. (2006). Prevalence of connexin 26 mutations in patients from jordan with non syndromic hearing loss. Int. J. Hum. Genet. 6, 119-124.

Maestrini, E., Korge, P.B., Ocana-Sierra, J., Calzolari, E., Cambiaghi, S., Scudder, M.P., Hovnanian, A., Monaco, P.A., and Munro, S.C. (1999). A missense mutation in connexin26, D66H, causes mutilating keratoderma with sensorineural deafness (Vohwinkel's syndrome) in three unrelated families. Hum. Mol. Genet. 8, 1237- 1243.

Marziano, K.N., Casalotti, O.S., Partelli, E.A., Becker, L.D., and Forage, A. (2003). Mutations in the gene for connexin 26 (GJB2) that cause hearing loss have a dominant negative effect on connexin 30. Hum. Mole. Genet. 12, 805-812.

Musil, L.S., and Goodenough, D.A. (1993). Multisubunit assembly of an integral plasma membrane channel protein, gap junction connexin43, occurs after exit from the ER. Cell 74, 1065-1077.

Richard, G., Brown, N., Ishida-Yamamoto, A., and Krol, A. (2004). Expanding the phenotypic spectrum of Cx26 disorders: bart-pumphrey syndrome is caused by a novel missense mutation in GJB2. J. Invest. Dermatol. 123, 856- 863 .

Saez, J.C., Branes. M.C., Corvalan, L.A., Eugenin, E.A., Gonzalez, H., Martinez, A.D., and Palisson, F. (2000). Gap junctions in cells of immune system: structure, regulation and possible functional roles. Braz. J. Med. Biol. Res. 33, 447-455.

Snoeckx, L.R., Hassan, M.D., Kamal, M.N., Bogaert, D.V.K., and Camp, V.G. (2005). Mutation analysis of the GJB2 (connexin 26) gene in egypt. J. Hum. Mut. 26, 60-61.

Sosinsky, G. (1995). Mixing of connexins in gap junction membrane channels. Proc. Natl. Acad. Sci. 92, 9210-9214.

Talley, K., Ng, C., Shoppell, M., Kundrotas, P., and Alexov, E. (2008). On the electrostatic component of protein-protein binding free energy PMC Biophysics 1:2 doi:10.1186/ 1757-5036-1-2. http://www.physmathcentral.com/1757-5036/1/2

Tremblay, K., and Ross, B. (2007). Effects of age and age-related hearing loss on the brain. J. Commun. Disorders 40, 305-312.

Williams, R.W., Chang, A., Juretic, D., and Loughran, S. (1987). Secondary structure predictions and medium range interactions. Biochim Biophys Acta. 916, 200-204.

Xiang, Z. (2006). Advances in homology protein structure modeling. Curr. Protein Pept. Sci. 7, 217-227.

Yotsumoto, S., Hashiguchi, T., Chen, X., Ohtake, N., Tomitaka, A., Akamatsu, H., Matsunaga, K., Shiraishi, S., Miura, H., Adachi, J., and Kanzaki, T. (2003). Novel mutations in GJB2 encoding connexin-26 in Japanese patients with keratitis-ichthyosis-deafness syndrome. $\mathrm{Br}$. J. Dermatol. 148, 649-653.

Zelante, L., Gasparini, P., Estivill, X., Melchionda, S., D'Agruma, L., Govea, N., Mila, M., Monica, M.D., Lutfi, J., Shohat, M., Mansfield E., Delgrosso, K., Rappaport, E., Surrey, S., and Fortina, P. (1997). Connexin26 mutations associated with the most common form of non-syndromic neurosensory autosomal recessive deafness (DFNB1) in Mediterraneans. Hum. Mol. Genet. 6, 1605-1609. 